\title{
The Impact of Tobacco Smoke Exposure on Wheezing and Overweight in 4-6-Year-Old Children
}

\author{
Regina Grazuleviciene, ${ }^{1}$ Sandra Andrusaityte, ${ }^{1}$ Inga Uzdanaviciute, ${ }^{1}$ Jolanta Kudzyte, \\ Rimantas Kevalas, ${ }^{2}$ and Mark J. Nieuwenhuijsen ${ }^{3}$ \\ ${ }^{1}$ Department of Environmental Science, Vytautas Magnus University, K. Donelaicio Street 58, 44248 Kaunas, Lithuania \\ ${ }^{2}$ Department of Children Diseases, Kaunas University of Medicine, Eiveniu Street 2, 50161 Kaunas, Lithuania \\ ${ }^{3}$ Centre for Research in Environmental Epidemiology (CREAL), Doctor Aiguader 88, 08003 Barcelona, Spain \\ Correspondence should be addressed to Regina Grazuleviciene; r.grazuleviciene@gmf.vdu.lt
}

Received 7 March 2014; Revised 8 June 2014; Accepted 24 June 2014; Published 6 July 2014

Academic Editor: Amy K. Ferketich

Copyright (C) 2014 Regina Grazuleviciene et al. This is an open access article distributed under the Creative Commons Attribution License, which permits unrestricted use, distribution, and reproduction in any medium, provided the original work is properly cited.

\begin{abstract}
Aim. To investigate the association between maternal smoking during pregnancy, second-hand tobacco smoke (STS) exposure, education level, and preschool children's wheezing and overweight. Methods. This cohort study used data of the KANC cohort1,489 4-6-year-old children from Kaunas city, Lithuania. Multivariate logistic regression was employed to study the influence of prenatal and postnatal STS exposure on the prevalence of wheezing and overweight, controlling for potential confounders. Results. Children exposed to maternal smoking during pregnancy had a slightly increased prevalence of wheezing and overweight. Postnatal exposure to STS was associated with a statistically significantly increased risk of wheezing and overweight in children born to mothers with lower education levels (OR 2.12; 95\% CI 1.04-4.35 and 3.57; 95\% CI 1.76-7.21, accordingly). Conclusions. The present study findings suggest that both maternal smoking during pregnancy and STS increase the risk of childhood wheezing and overweight, whereas lower maternal education might have a synergetic effect. Targeted interventions must to take this into account and address household smoking.
\end{abstract}

\section{Introduction}

Exposure of nonsmoking women to second-hand tobacco smoke (STS) during pregnancy is a serious threat to public health and is a significant cause of damage to the immune system of the fetuses. There is growing evidence that in utero exposure to tobacco smoke adversely affects postnatal lung function and increases the risk of allergic disease [1-6] and also affects infants' physical development and overweight in later life [7-10]. The recent systemic review of wheezing in childhood [11] has suggested that exposure to STS increases the risk of wheezing. Epidemiological studies have revealed that exposure to passive smoke-particularly prenatal or postnatal maternal smoking-is associated with increased risks (from $28 \%$ to $70 \%$ ) of wheeze in children aged 5 to 18 years [12-16]. Some authors reported that maternal smoking increases the risk of allergic sensitization and wheezing only in children with allergic predisposition [16-18] and that interaction of genetic and environmental risk factors has an impact on the incidence and prognosis of wheezing illness during childhood [19-22]. There is evidence that both socioenvironmental factors and tobacco smoke may influence the development of asthma or wheezing $[17,18,20$, 22-24].

Now it has been recognized that exposure to passive smoking is an important risk factor for the incidence of wheeze and asthma during childhood. Less frequently reported associations include children's physical development, overweight, and obesity $[25,26]$. The studies of childhood overweight have reported far less consistent results [10, 27-29], and causal relations between exposure to smoking in utero and childhood overweight lack evidence.

There is speculation that the effect of intrauterine tobacco exposure on childhood obesity may depend largely on cigarette smoking during the first trimester, whereas the additional impact of smoking throughout pregnancy might 
be due to confounding by sociodemographics [8] or residual confounding by genetic and family environmental factors $[7,10]$. However, a systematic review of studies reporting on the association between maternal prenatal cigarette smoking and elevated risk for childhood overweight suggested that sociodemographic and behavioral differences between smokers and nonsmokers did not explain the observed association [26]. The review suggested that prenatal smoke exposure led to about $50 \%$ increase in the risk of being overweight in childhood. Based on the meta-analysis, the authors' findings showed that children whose mothers smoked during pregnancy were at an elevated risk for overweight (pooled adjusted odds ratio $1.50,95 \%$ CI 1.36-1.65), compared with children whose mothers did not smoke during pregnancy $[25,30,31]$. The findings of a population-based prospective cohort study suggested that direct intrauterine exposure to smoke until late pregnancy leads to different height and weight growth adaptations and an increased risk of overweight and obesity in preschool children [32]. It has been suggested that maternal smoking during pregnancy increases the risk of obesity in the offspring [9,33]; however, additional studies are needed to assess directly whether smoking in early pregnancy increases long-term risk of obesity-related disorders in children [34]. Only a few studies have explored the impact of sociodemographics factors of STS on preschool children health $[5,35,36]$.

In the present study, using individual cohort study data, we investigated the association between STS during pregnancy in nonsmoking and smoking mothers, the individuallevel socioeconomic status (SES), and wheezing and overweight in 4-6-year-old children. We hypothesized that the effects would be more apparent in children born to mothers with lower rather than higher level of education.

\section{Methods}

2.1. Study Population. The data used in these analyses were collected as part of the PHENOTYPE project (Positive Health Effects of the Natural Outdoor Environment in Typical Populations in Different Regions in Europe) funded by the European Commission Seventh Framework Program [37]. We used survey data on women who were recruited to the pregnant women cohort study during 2007-2009. The first interview was completed during the first trimester of pregnancy. Women reported their age at inclusion (less than 30 years or 30 years and older), education level (low-10 or fewer years, medium and high-more than 10 years), social status (worker, student, unemployed-low; housekeeper, officermedium; manager, company owner-high), marital status (married or not married), smoking (nonsmoker or smokes at least one cigarette per day), maternal body mass index (BMI) $(<25,25-30$, or $>30 \mathrm{~kg} / \mathrm{m} 2)$, and other variables. Active maternal smoking at enrollment was assessed in the first questionnaire by asking whether the mother smoked during her pregnancy. The second interview was completed just after childbirth $(76 \%)$ or by telephone within the first month after delivery (24\%), and data on residential history, job during pregnancy, health behavior, and other variables were collected. Individual-level SES predictors were education level and occupation type. Postal questionnaires sent in 2013 at children's ages 4-6 years provided information about children's health. Information collected from the mothers included details on the exposure to tobacco smoke. However, because of the relatively small number of smoking mothers in the sample, we chose not to divide this group into smaller categories.

In this study, we investigated the influence of maternal exposure to domestic cigarette smoke during pregnancy on the prevalence of wheezing and being overweight in the children. We separately analyzed mothers who themselves smoked during their pregnancy from those who did not but were exposed to domestic cigarette smoking. The participants were 1,489 children residing in Kaunas city, Lithuania, who in 2013 were 4-6 years of age and whose parents or guardians responded to questionnaire and agreed to participate in the study. The study was approved by the Lithuanian Bioethics Committee, and parental informed consent was obtained from all participants. Questionnaire responses by parents or guardians were used to categorize children's basic information, medical history, family history, personal habits, children's height and weight, and housing and environmental conditions. Responses to the standardized International Study of Asthma and Allergies in Childhood (ISAAC) questionnaire completed by parents were used to identify children with symptoms of wheezing. Wheezing during the last 12 months was identified by an affirmative response to the question: "Has your child experienced wheezing (whistling sounds in the chest) over the last 12 months?" The outcome measure was wheezing during last 12 months and a variety of social and environmental factors were taken into account.

To assess children's overweight, their BMI was calculated as the ratio of weight (in $\mathrm{kg}$ )/height (in $\mathrm{m} 2$ ). To define overweight and obese in our study, we used age group and sex-fixed BMI cutoff points recommended for the evaluation of overweight and obesity in children according to the Childhood Obesity Working Group of the International Obesity Taskforce (IOTF) guidelines [38]. BMI classes were evaluated according to the IOTF: underweight (BMI $\leq 14 \mathrm{~kg} / \mathrm{m} 2)$; normal weight (BMI $>14 \mathrm{~kg} / \mathrm{m} 2$ and $<18 \mathrm{~kg} / \mathrm{m} 2$ ); overweight $(B M I \geq 18 \mathrm{~kg} / \mathrm{m} 2$ and $<20 \mathrm{~kg} / \mathrm{m} 2)$; and obesity (BMI $\geq$ $20 \mathrm{~kg} / \mathrm{m} 2)$. Because of the small number of obese children $(N=36)$, overweight and obese groups were merged in the analysis.

2.2. Statistical Analysis. We used chi-square and univariate logistic regression analyses to compare values and frequencies of the baseline characteristics by smoking status of the study subjects. Subsequently, we evaluated the associations among the covariates that are known to be related to an increased risk of wheezing and overweight. Predictor variables whose univariate test showed a statistically significant association $(P<0.05)$ with the outcome-or those that changed the adjusted odds ratios (aOR) by $10 \%$ or morewere retained for inclusion in multivariate logistic regression analyses. 
Multivariate logistic regressions were used to assess the relationship between the prevalence of wheezing in STSexposed and nonexposed women's children, adjusting for the mothers' education level, the children's sex, birth weight, and antibiotic use during the first year of life; and for overweight adjusting for the mothers' education level, the children's sex, birth weight, and time spent at the computer. The group of women who had not smoked during their pregnancy and had no STS exposure was used as the reference group. Subsequently, we conducted a stratified analysis where we compared the reference group of children whose mothers were well educated and smoked during pregnancy with children born to mothers with lower education levels. The effect of STS on wheezing and overweight in children was estimated as unadjusted and adjusted odds ratios with 95\% confidence intervals (CI). All statistical analyses were performed using SPSS version 18.0 (SPSS Inc. Released 2009. PASW Statistics for Windows, Version 18.0. Chicago: SPSS Inc.).

\section{Results}

The women who participated in the study were highly educated; $73.1 \%$ of them had more than 10 years of education and a university degree. As many as $92.4 \%$ of the mothers reported never having smoked; however, $35.8 \%$ of them had been exposed to STS at home. Maternal smoking during pregnancy was associated with a younger age, lower education level, low socioeconomic status, a lower prevalence of breastfeeding, and postnatal antibiotic usage during the first year. Wheezing during the last 12 months in children was associated with a lower maternal education level, parental asthma, male sex, the number of siblings, and antibiotic use during the first year of life (Table 1). The prevalence of wheezing among children of nonsmoking mothers was $10.9 \%$ and among children born to mothers who were smoking during pregnancy was $15.9 \%$. Among lower educated mothers it was $16.9 \%$ while in medium or high educated mothers it was $9.8 \%$, crude OR $1.87,95 \%$ CI $1.29-2.71$.

The analysis of the distribution of risk factors for overweight showed that lower maternal education level, smoking during pregnancy, male sex, birth weight over $3500 \mathrm{~g}$, and more than one hour per day spent at the computer increased the prevalence of overweight among 4-6-year-old children (Table 2). The prevalence of overweight among children of lower educated mothers was $11.7 \%$ while among medium or high educated mothers it was $6.3 \%$, crude OR $2.00,95 \%$ CI 1.30-3.00.

Table 3 shows the results of multivariate logistic regression models analyzing the association between maternal educations, STS, and wheezing among 4-6-year-old children. The multivariate model showed that, with reference to the group of nonsmoking women with a high education level and no STS exposure, STS exposure was found to be a statistically significant risk factor for wheezing in children born to mothers with lower education levels, after adjustment for antibiotic use during the first year of life, low birth weight, and child parity. Among nonsmokers mothers with lower education levels, the presence of household smoking was found to increase the risk of children wheezing to $1.96,95 \% \mathrm{CI}$ $1.28-2.98$ and among smoking mothers to 2.12 , 95\% CI 1.044.35. The interaction term between lower education level, smoking, and children sex is not statistically significant $(\mathrm{OR}=$ 1.89, $P=0.20)$.

Table 4 presents the results of multivariate logistic regression models analyzing the association between maternal education levels, STS, and overweight in 4-6-year-old children. With reference to the group of high educated nonsmoking women with no STS exposure, the presence of STS exposure was found to be a significant risk factor for overweight in children, after adjusting for birth weight and time spent at the computer. The mothers' lower education levels and smoking during pregnancy, as well as STS exposure, increased the odds ratios of overweight in children to $3.57,95 \%$ CI 1.76-7.21.

\section{Discussion}

This study demonstrated that STS increased the risk of wheeze for 4-6-year-old children who were not exposed (the mother was a nonsmoker) or exposed (the mother was a smoker) to maternal tobacco smoke while in utero; however, a statistically significant effect was evident only for children born to mothers with lower education levels (OR 1.96 and 2.12 , accordingly). Using well-educated nonsmoking mothers not exposed to STS as a reference group, we did not find that household STS exposure had any statistically significant effect on the risk of wheezing in children of mothers with higher education levels. The effect of tobacco smoke on overweight was also higher among children of mothers with lower education levels. The odds ratio for overweight associated with tobacco smoke exposure was 3.57.

In this study, maternal smoking status was dichotomized to smoking and nonsmoking. The mothers who smoked during pregnancy tended to be different from nonsmokers in variables that also predicted the risk of child wheezing and overweight. In general, smokers were younger, were less educated, had a lower socioeconomic status, and were less likely to breastfeed, and their children more often used antibiotic during the first year of life. We found that among 4-6-year-old children of these women, maternal smoking status and STS had a relation with both wheezing and overweight, which was independent of maternal educational level, maternal age, and other variables that we adjusted for.

For the interpretation of this study, a few issues should be taken into account. Using individual data, we addressed possible confounding variables in multivariate analyses and estimated the effects of STS exposure on wheezing and overweight separately for the groups of children born to nonsmoking and smoking mothers with higher and lower education levels. Data on wheezing and overweight were obtained from parental reports through a questionnaire; the evaluation of exposure to tobacco smoke was indirect, and thus the possibility of random reporting bias exists. However, in this study, we controlled for the main variables that might confound the association between tobacco smoke exposure and children's wheezing and overweight-education level and first-year postnatal antibiotic use among them which 
TABLE 1: Distribution of variables according to wheezing during the last 12 months among children and unadjusted effects as odds ratios (OR) and $95 \%$ confidence intervals (CI).

\begin{tabular}{|c|c|c|c|}
\hline Variables & $\begin{array}{c}\text { Wheezing yes } \\
N(\%)\end{array}$ & $\begin{array}{c}\text { Wheezing no } \\
N(\%)\end{array}$ & $\begin{array}{c}\text { Odds ratios }^{* *} \\
95 \% \mathrm{CI}\end{array}$ \\
\hline \multicolumn{4}{|c|}{ Mother's age at childbirth (years) } \\
\hline$<30$ & $110(11.1 \%)$ & $885(88.9 \%)$ & 1 \\
\hline 31 and more & $58(11.7 \%)$ & $436(88.3 \%)$ & $1.07(0.75-1.52)$ \\
\hline \multicolumn{4}{|l|}{ Maternal education level } \\
\hline Low $\left(10\right.$ or less years) ${ }^{*}$ & $52(16.9 \%)$ & $255(83.1 \%)$ & $1.87(1.29-2.71)$ \\
\hline Medium, high (>10 years) & $116(9.8 \%)$ & $1066(90.2 \%)$ & 1 \\
\hline \multicolumn{4}{|l|}{ Socioeconomic status } \\
\hline Low & $50(12.5 \%)$ & $351(87.5 \%)$ & $1.17(0.81-1.69)$ \\
\hline Moderate, high & $118(10.8 \%)$ & $970(89.2 \%)$ & 1 \\
\hline \multicolumn{4}{|c|}{ Maternal smoking during pregnancy } \\
\hline No & $150(10.9 \%)$ & $1226(89.1 \%)$ & 1 \\
\hline Yes & $18(15.9 \%)$ & $95(84.1 \%)$ & $1.55(0.88-2.71)$ \\
\hline \multicolumn{4}{|l|}{ Maternal secondhand smoking } \\
\hline No & $98(10.3 \%)$ & $858(89.7 \%)$ & 1 \\
\hline Yes & $70(13.1 \%)$ & $463(86.9 \%)$ & $1.32(0.94-1.86)$ \\
\hline \multicolumn{4}{|l|}{ Gas cooking } \\
\hline No & $52(9.7 \%)$ & $483(90.3 \%)$ & 1 \\
\hline Yes & $116(12.2 \%)$ & $838(87.8 \%)$ & $1.29(0.90-1.84)$ \\
\hline \multicolumn{4}{|l|}{ Children's sex } \\
\hline Male ${ }^{*}$ & $103(14.0 \%)$ & $635(86.0 \%)$ & $1.71(1.22-2.41)$ \\
\hline Female & $65(8.7 \%)$ & $686(91.3 \%)$ & 1 \\
\hline \multicolumn{4}{|l|}{ Children parity } \\
\hline 1 & $79(9.6 \%)$ & $743(90.4 \%)$ & 1 \\
\hline 2 and more ${ }^{*}$ & $89(13.3 \%)$ & $578(86.7 \%)$ & $1.45(1.04-2.02)$ \\
\hline \multicolumn{4}{|l|}{ Birth weight } \\
\hline$<2500 \mathrm{~g}$ & $14(15.4 \%)$ & $77(84.6 \%)$ & $1.47(0.77-2.74)$ \\
\hline $2501 \mathrm{~g}$ and more & $154(11.0 \%)$ & $1244(89.0 \%)$ & 1 \\
\hline \multicolumn{4}{|l|}{ Breastfeeding } \\
\hline No & $16(16.2 \%)$ & $83(83.8 \%)$ & $1.57(0.86-2.83)$ \\
\hline Yes & $152(10.9 \%)$ & $1238(89.1 \%)$ & 1 \\
\hline \multicolumn{4}{|l|}{ Allergy } \\
\hline No & $61(5.9 \%)$ & $973(94.1 \%)$ & 1 \\
\hline Yes $^{*}$ & $107(23.5 \%)$ & $348(76.5 \%)$ & $4.90(3.45-6.97)$ \\
\hline \multicolumn{4}{|l|}{ Eczema } \\
\hline No & $148(10.7 \%)$ & $1240(89.3 \%)$ & 1 \\
\hline Yes $^{*}$ & $20(19.8 \%)$ & $81(80.2 \%)$ & $2.07(1.19-3.57)$ \\
\hline \multicolumn{4}{|c|}{ Paracetamol use during the first year of life } \\
\hline No & $41(9.1 \%)$ & $412(90.9 \%)$ & 1 \\
\hline Yes & $127(12.3 \%)$ & $909(87.7 \%)$ & $1.40(0.95-2.07)$ \\
\hline \multicolumn{4}{|c|}{ Antibiotic use during the first year of life } \\
\hline No & $75(7.7 \%)$ & $899(92.3 \%)$ & 1 \\
\hline Yes $^{*}$ & $93(18.1 \%)$ & $422(81.9 \%)$ & $2.64(1.88-3.71)$ \\
\hline \multicolumn{4}{|l|}{ Asthma in parents } \\
\hline No & $140(10.1 \%)$ & $1251(89.9 \%)$ & 1 \\
\hline Yes* $^{*}$ & $28(28.6 \%)$ & $70(71.4 \%)$ & $3.57(2.17-5.87)$ \\
\hline
\end{tabular}


TABLE 2: Distribution of variables according to children's overweight status and unadjusted effects as odds ratios (OR) and 95\% confidence intervals $(\mathrm{CI})$.

\begin{tabular}{|c|c|c|c|}
\hline Risk factors & $\begin{array}{c}\text { Overweight yes } \\
\qquad N(\%)\end{array}$ & $\begin{array}{c}\text { Overweight no } \\
N(\%)\end{array}$ & $\begin{array}{c}\text { Odds ratios }^{* *} \\
95 \% \text { CI }\end{array}$ \\
\hline \multicolumn{4}{|c|}{ Mothers' age at childbirth (years) } \\
\hline$<30$ & $79(7.9 \%)$ & $916(92.1 \%)$ & $1.25(0.81-1.91)$ \\
\hline 31 and more & $32(6.5 \%)$ & $426(93.5 \%)$ & 1 \\
\hline \multicolumn{4}{|l|}{ Maternal education level } \\
\hline Low (10 or less years) ${ }^{*}$ & $36(11.7 \%)$ & $271(88.3 \%)$ & $2.00(1.30-3.00)$ \\
\hline Medium, high ( $>10$ years) & $75(6.3 \%)$ & $1107(93.7 \%)$ & 1 \\
\hline \multicolumn{4}{|l|}{ Maternal active smoking* } \\
\hline No & $88(6.8 \%)$ & $1212(93.2 \%)$ & 1 \\
\hline Yes & $23(12.2 \%)$ & $166(87.8 \%)$ & $1.91(1.17-3.11)$ \\
\hline \multicolumn{4}{|c|}{ Maternal smoking during pregnancy* } \\
\hline No & $94(6.8 \%)$ & $1282(93.2 \%)$ & 1 \\
\hline Yes & $17(15.0 \%)$ & $96(85.0 \%)$ & $2.42(1.38-4.21)$ \\
\hline \multicolumn{4}{|l|}{ Maternal second-hand smoking } \\
\hline No & $68(7.1 \%)$ & $888(92.9 \%)$ & 1 \\
\hline Yes & $43(8.1 \%)$ & $490(91.9 \%)$ & $1.15(0.77-1.71)$ \\
\hline \multicolumn{4}{|l|}{ Children's sex } \\
\hline Male ${ }^{*}$ & $65(8.8 \%)$ & $673(91.2 \%)$ & $1.48(1.00-2.19)$ \\
\hline Female & $46(6.1 \%)$ & $705(93.9 \%)$ & 1 \\
\hline \multicolumn{4}{|l|}{ Breastfeeding } \\
\hline No & $10(10.1 \%)$ & $89(89.9 \%)$ & $1.43(0.72-2.84)$ \\
\hline Yes & $101(7.3 \%)$ & $1289(92.7 \%)$ & 1 \\
\hline \multicolumn{4}{|c|}{ Paracetamol use during the first year of life } \\
\hline No & $26(5.7 \%)$ & $427(94.3 \%)$ & 1 \\
\hline Yes & $85(8.2 \%)$ & $951(91.8 \%)$ & $1.47(0.93-2.31)$ \\
\hline \multicolumn{4}{|c|}{ Antibiotic use during the first year of life } \\
\hline No & $66(6.8 \%)$ & $908(93.2 \%)$ & 1 \\
\hline Yes & $45(8.7 \%)$ & $470(91.3 \%)$ & $1.32(0.89-1.96)$ \\
\hline \multicolumn{4}{|l|}{ Birth weight* } \\
\hline$<2500 \mathrm{~g}$ & $6(6.8)$ & $82(93.2 \%)$ & $1.17(0.48-2.84)$ \\
\hline $2500-3500 \mathrm{~g}$ & $43(5.9 \%)$ & $688(94.1 \%)$ & 1 \\
\hline$>3500 \mathrm{~g}$ & $62(9.3 \%)$ & $608(90.7 \%)$ & $1.63(1.09-2.44)$ \\
\hline \multicolumn{4}{|l|}{ Watching TV } \\
\hline$\leq 1 \mathrm{~h} /$ day & $36(6.1 \%)$ & $558(93.9 \%)$ & 1 \\
\hline$>1 \mathrm{~h} /$ day & $75(8.4 \%)$ & $820(91.6 \%)$ & $1.42(0.94-2.14)$ \\
\hline \multicolumn{4}{|l|}{ Time spent at the computer* } \\
\hline$\leq 1 \mathrm{~h} /$ day & $72(6.3 \%)$ & $1066(93.7 \%)$ & 1 \\
\hline$>1 \mathrm{~h} /$ day & $39(11.1 \%)$ & $312(88.9 \%)$ & $1.58(2.84-6.47)$ \\
\hline
\end{tabular}

${ }^{*} P<0.05$.

** Unadjusted associations are presented as overweight odds ratio (OR) with $95 \%$ confidence intervals of univariate analysis.

could attenuate the strengths of the observed associations. Because of the low prevalence of maternal smoking during pregnancy, the sample size was insufficient to obtain statistically significant results during stratified analyses for the some estimation. Our similar estimates for unadjusted and adjusted associations suggest that sociodemographic and other differences between smokers and nonsmokers did not explain the observed association. These data are consistent with those obtained in studies from other countries $[8,31,39$, 40].

The results of our study are in accordance with those from other studies regarding the observed effects of tobacco smoke on the risk of overweight. As in other studies, lower maternal educational level $[41,42]$ and longer duration of 
TABLE 3: Association of maternal education level, second-hand tobacco smoke (STS), and wheezing in 4-6-year-old children with reference to well-educated nonexposed to tobacco smoke mothers.

\begin{tabular}{lcc}
\hline $\begin{array}{l}\text { Maternal education level } \\
\text { and smoking }\end{array}$ & $\begin{array}{c}\text { Wheezing cases } \\
N(\%)\end{array}$ & $\begin{array}{c}\text { Adjusted risk of } \\
\text { wheezing* } \\
\text { aOR }(95 \% \mathrm{CI})\end{array}$ \\
\hline $\begin{array}{l}\text { Mother nonsmoker } \\
\text { High and no STS** }\end{array}$ & $72(8.9 \%)$ & 1 (reference) \\
High and STS & $37(11.6 \%)$ & $1.32(0.86-2.02)$ \\
Low and STS & $41(16.5 \%)$ & $1.96(1.28-2.98)$ \\
Mother smoker & $72(8.9 \%)$ & 1 (reference) \\
High and no STS** & $7(12.7 \%)$ & $1.26(0.54-2.93)$ \\
High and STS & $11(19.0 \%)$ & $2.12(1.04-4.35)$ \\
Low and STS &
\end{tabular}

${ }^{*}$ Results of multivariate logistic regression models are presented as associations of wheezing odds ratio (OR) with $95 \%$ confidence intervals adjusting for first-year postnatal antibiotic use, low birth weight, and child parity. ${ }^{* * *}$ Reference category is high educated, nonsmokers, and nonexposed to second-hand tobacco smoke (STS) mothers. SES-specific STS effect on children wheezing is presented in nonsmoker mothers and smoker mothers by educational level.

children spent watching television and playing electronic games $[43,44]$ were associated with risk of being overweight. The observed association between smoking early in pregnancy and childhood obesity could be explained through metabolism disorder produced by tobacco smoke, which can result in reduced blood supply to the fetus because of the constrictive effects of blood vessels on maternal and uteroplacental blood supply [8].

Selection bias within the study population with such a difference in respondents and in nonrespondents groups should not lead to systematic bias because of the absence of a systematic difference in birth outcomes between the two response groups. Although we did adjust our analysis for proxy indicators of wheezing and overweight in children, we cannot exclude that residual noncontrolled confounding variables may affect the observed higher risk for wheezing and overweight in exposed children of mothers with lower education levels because of less healthy lifestyle habits [26]. This study did not include measures linked to genetic factors that are strongly associated with cigarette smoking. Therefore, there may well be residual genetic confounding that links the response to early-life tobacco smoke exposure with allergies and metabolic disorders later in life. The results of our previously published study suggested that smoking, even at low levels, ought to be considered a potential risk factor for adverse birth outcomes and that genetic polymorphism may contribute to individual variation in response to tobacco smoke [45].

A variety of adverse health outcomes are linked to cigarette smoking before and during pregnancy, and there are no speculations about the possible difference in health effects by children's sex. Maternal prenatal cigarette smoke damages the antioxidant system, has a negative impact on both the mother and the fetus on the genetic and cellular levels, and might disturb the development of the immune system in the fetus $[1,46]$. Genetic polymorphism associated with airway
TABLE 4: Association of maternal education level, second-hand tobacco smoke (STS), and overweight in 4-6-year-old children with reference to well-educated nonexposed to tobacco smoke mothers.

\begin{tabular}{lcc}
\hline $\begin{array}{l}\text { Maternal education level } \\
\text { and smoking }\end{array}$ & $\begin{array}{c}\text { Overweight cases } \\
N(\%)\end{array}$ & $\begin{array}{c}\text { Adjusted risk of } \\
\text { overweight* } \\
\text { aOR }(95 \% \text { CI) }\end{array}$ \\
\hline $\begin{array}{l}\text { Mother nonsmoker } \\
\text { High and no STS** }\end{array}$ & $53(6.6 \%)$ & 1 (reference) \\
High and STS & $17(5.3 \%)$ & $0.80(0.46-1.41)$ \\
Low and STS & $24(9.6 \%)$ & $1.40(0.84-2.34)$ \\
Mother smoker & $53(6.6 \%)$ & 1 (reference) \\
$\quad$ High and no STS ${ }^{* *}$ & $5(9.1 \%)$ & $1.29(0.49-3.41)$ \\
High and STS & $12(20.7 \%)$ & $3.57(1.76-7.21)$ \\
\hline Low and STS &
\end{tabular}

${ }^{*}$ Results of stratified multivariate logistic regression models are presented as associations of overweight odds ratio (OR) with 95\% confidence intervals adjusting for first-year postnatal antibiotic use, low birth weight, and time spent at the computer. ${ }^{* *}$ Reference category is high educated, nonsmokers, and nonexposed to second-hand tobacco smoke (STS) mothers. SES-specific STS effect on overweight is presented in nonsmoker mothers and smoker mothers by educational level.

hyperresponsiveness also has an impact on the expression of asthma symptoms $[18,47]$.

There is evidence that the impact of tobacco smoke on wheezing and being overweight in individual children is not on a par and that individual genetic predisposition may have an impact on the prognosis of children's health [16, $17,26,27]$. Previous studies have suggested several plausible explanations for the gene-smoking interaction. Glutathione S-transferase (GST) M1 enzyme product that is involved in detoxification of both reactive tobacco metabolic intermediates and reactive oxygen species (GSTM1) null genotype has been shown to modify the effects of fetal tobacco smoke exposure on childhood asthma and wheezing [20, 48-50]. It has also been shown that maternal smoking during pregnancy is related to changes in DNA methylation $[51,52]$. However, whether these changes underlie the associations between tobacco smoke exposure and children's obesity remains vague [32].

In conclusion, the mechanisms by which maternal smoking during pregnancy and STS may program children's postnatal health need to be studied further. Our results suggested that exposure to active maternal smoking during fetal development as well as later STS exposure led to an increased risk for wheezing and obesity in 4-6-year-old children. These results underlined the importance of health care interventions helping to quit smoking prior to conception and that targeted interventions must comprise cessation of household smoking for the prevention of chronicle diseases such as allergies and obesity in their children. Future studies are needed in children to identify the associations and interactions of socioenvironmental factors, tobacco smoke, and genetic predisposition to allergy and metabolic disorders.

\section{Conflict of Interests}

The authors declare that there is no conflict of interests. 


\section{Acknowledgments}

This work was supported in part by the European Commission Grant no. FP6-036224; the original study on which the present paper is based received Grant no. FP7-282996 and Grant of Lithuanian Agency for Science Innovation and Technology (MITA), no. 2012-07-20 No 31V-125.

\section{References}

[1] F. D. Gilliland, K. Berhane, R. McConnell et al., "Maternal smoking during pregnancy, environmental tobacco smoke exposure and childhood lung function," Thorax, vol. 55, no. 4, pp. 271-276, 2000.

[2] J. J. K. Jaakkola, P. Nafstad, and P. Magnus, "Environmental tobacco smoke, parental atopy, and childhood asthma," Environmental Health Perspectives, vol. 109, no. 6, pp. 579-582, 2001.

[3] K. L. Vork, R. L. Broadwin, and R. J. Blaisdell, "Developing asthma in childhood from exposure to secondhand tobacco smoke: insights from a meta-regression," Environmental Health Perspectives, vol. 115, no. 10, pp. 1394-1400, 2007.

[4] W. K. Midodzi, B. H. Rowe, C. M. Majaesic, L. D. Saunders, and A. Senthilselvan, "Predictors for wheezing phenotypes in the first decade of life," Respirology, vol. 13, no. 4, pp. 537-545, 2008.

[5] L. Duijts, V. W. V. Jaddoe, R. J. P. van der Valk et al., "Fetal exposure to maternal and paternal smoking and the risks of wheezing in preschool children: the generation R study," Chest, vol. 141, no. 4, pp. 876-885, 2012.

[6] Å. Neuman, C. Hohmann, N. Orsini et al., "Maternal smoking in pregnancy and asthma in preschool children: a pooled analysis of eight birth cohorts," American Journal of Respiratory and Critical Care Medicine, vol. 186, no. 10, pp. 1037-1043, 2012.

[7] C. Power and B. J. M. H. Jefferis, "Fetal environment and subsequent obesity: a study of maternal smoking," International Journal of Epidemiology, vol. 31, no. 2, pp. 413-419, 2002.

[8] A. M. Toschke, S. M. Montgomery, U. Pfeiffer, and R. Von Kries, "Early intrauterine exposure to tobacco-inhaled products and obesity," The American Journal of Epidemiology, vol. 158, no. 11, pp. 1068-1074, 2003.

[9] R. von Kries, A. M. Toschke, B. Koletzko, and W. Slikker Jr., "Maternal smoking during pregnancy and childhood obesity," American Journal of Epidemiology, vol. 156, no. 10, pp. 954-961, 2002.

[10] S. Yang, A. Decker, and M. S. Kramer, "Exposure to parental smoking and child growth and development: a cohort study," BMC Pediatrics, vol. 13, no. 1, article 104, 2013.

[11] H. Burke, J. Leonardi-Bee, A. Hashim et al., "Prenatal and passive smoke exposure and incidence of asthma and wheeze: systematic review and meta-analysis," Pediatrics, vol. 129, no. 4, pp. 735-744, 2012.

[12] A. M. B. Menezes, P. C. Hallal, A. Muiño, M. Chatkin, C. L. P. Araújo, and F. C. Barros, "Risk factors for wheezing in early adolescence: a prospective birth cohort study in Brazil," Annals of Allergy, Asthma \& Immunology, vol. 98, no. 5, pp. 427-431, 2007.

[13] S. A. Lewis and J. R. Britton, "Consistent effects of high socioeconomic status and low birth order, and the modifying effect of maternal smoking on the risk of allergic disease during childhood," Respiratory Medicine, vol. 92, no. 10, pp. 1237-1244, 1998.
[14] F. D. Martinez, A. L. Wright, L. M. Taussig et al., "Asthma and wheezing in the first six years of life," The New England Journal of Medicine, vol. 332, no. 3, pp. 133-138, 1995.

[15] N. C. Nicolaou, A. Simpson, L. A. Lowe, C. S. Murray, A. Woodcock, and A. Custovic, "Day-care attendance, position in sibship, and early childhood wheezing: a population-based birth cohort study," Journal of Allergy and Clinical Immunology, vol. 122, no. 3, pp. 500.e5-506.e5, 2008.

[16] T. Keil, S. Lau, S. Roll et al., "Maternal smoking increases risk of allergic sensitization and wheezing only in children with allergic predisposition: longitudinal analysis from birth to 10 years," Allergy, vol. 64, no. 3, pp. 445-451, 2009.

[17] M. Sørensen, L. Allermann, U. Vogel et al., "Polymorphisms in inflammation genes, tobacco smoke and furred pets and wheeze in children," Pediatric Allergy and Immunology, vol. 20, no. 7, pp. 614-623, 2009.

[18] K. J. Haley, J. Lasky-Su, S. E. Manoli et al., "RUNX transcription factors: association with pediatric asthma and modulated by maternal smoking," The American Journal of Physiology: Lung Cellular and Molecular Physiology, vol. 301, no. 5, pp. L693-L701, 2011.

[19] D. P. Strachan, B. K. Butland, and H. R. Anderson, "Incidence and prognosis of asthma and wheezing illness from early childhood to age 33 in a national British cohort," British Medical Journal, vol. 312, no. 7040, pp. 1195-1199, 1996.

[20] M. Cheraghi and S. Salvi, "Environmental tobacco smoke (ETS) and respiratory health in children," European Journal of Pediatrics, vol. 168, no. 8, pp. 897-905, 2009.

[21] A. J. Henderson, R. B. Newson, M. Rose-Zerilli, S. M. Ring, J. W. Holloway, and S. O. Shaheen, "Maternal Nrf2 and gluthathioneS-transferase polymorphisms do not modify associations of prenatal tobacco smoke exposure with asthma and lung function in school-aged children," Thorax, vol. 65, no. 10, pp. 897902, 2010.

[22] D. Daley, M. Lemire, L. Akhabir et al., "Analyses of associations with asthma in four asthma population samples from Canada and Australia," Human Genetics, vol. 125, no. 4, pp. 445-459, 2009.

[23] R. I. Ehrlich, D. Du Toit, E. Jordaan et al., "Risk factors for childhood asthma and wheezing: importance of maternal and household smoking," The American Journal of Respiratory and Critical Care Medicine, vol. 154, no. 3 I, pp. 681-688, 1996.

[24] L. M. Mills, S. E. Semple, I. S. Wilson et al., "Factors influencing exposure to secondhand smoke in preschool children living with smoking mothers," Nicotine and Tobacco Research, vol. 14, no. 12, pp. 1435-1444, 2012.

[25] A. Chen, M. L. Pennell, M. A. Klebanoff, W. J. Rogan, and M. P. Longnecker, "Maternal smoking during pregnancy in relation to child overweight: follow-up to age 8 years," International Journal of Epidemiology, vol. 35, no. 1, pp. 121-130, 2006.

[26] E. Oken, E. B. Levitan, and M. W. Gillman, "Maternal smoking during pregnancy and child overweight: systematic review and meta-analysis," International Journal of Obesity, vol. 32, no. 2, pp. 201-210, 2008.

[27] J. J. Reilly, J. Armstrong, A. R. Dorosty et al., "Early life risk factors for obesity in childhood: cohort study," The British Medical Journal, vol. 330, article 1357, no. 7504, 2005.

[28] A. Matijasevich, M.-J. Brion, A. M. Menezes, A. J. D. Barros, I. S. Santos, and F. C. Barros, "Maternal smoking during pregnancy and offspring growth in childhood: 1993 and 2004 Pelotas cohort studies," Archives of Disease in Childhood, vol. 96, no. 6, pp. 519-525, 2011. 
[29] L. D. Howe, A. Matijasevich, K. Tilling et al., "Maternal smoking during pregnancy and offspring trajectories of height and adiposity: comparing maternal and paternal associations," International Journal of Epidemiology, vol. 41, no. 3, Article ID dys025, pp. 722-732, 2012.

[30] L. Dubois and M. Girard, "Early determinants of overweight at 4.5 years in a population-based longitudinal study," International Journal of Obesity, vol. 30, no. 4, pp. 610-617, 2006.

[31] E. Oken, S. Y. Huh, E. M. Taveras, J. W. Rich-Edwards, and M. W. Gillman, "Associations of maternal prenatal smoking with child adiposity and blood pressure," Obesity Research, vol. 13, no. 11, pp. 2021-2028, 2005.

[32] B. Durmuş, C. J. Kruithof, M. H. Gillman et al., "Parental smoking during pregnancy, early growth, and risk of obesity in preschool children: the Generation R Study," The American Journal of Clinical Nutrition, vol. 94, no. 1, pp. 164-171, 2011.

[33] T. Ino, "Maternal smoking during pregnancy and offspring obesity: meta-analysis," Pediatrics International, vol. 52, no. 1, pp. 94-99, 2010.

[34] M. A. Mendez, M. Torrent, C. Ferrer, N. Ribas-Fitó, and J. Sunyer, "Maternal smoking very early in pregnancy is related to child overweight at age 5-7 y," American Journal of Clinical Nutrition, vol. 87, no. 6, pp. 1906-1913, 2008.

[35] C. Strong and L. Y. Chang, "Family socioeconomic status, household tobacco smoke, and asthma attack among children below 12 years of age: gender differences," Journal of Child Health Care, 2013.

[36] J. J. K. Jaakkola and M. Gissler, "Are girls more susceptible to the effects of prenatal exposure to tobacco smoke on asthma?" Epidemiology, vol. 18, no. 5, pp. 573-576, 2007.

[37] M. J. Nieuwenhuijsen, H. Kruize, C. Gidlow et al., "Positive health effects of the natural outdoor environment in typical population in different regions in Europe," BMJ Open, vol. 4, Article ID e004951, 2014.

[38] T. J. Cole, K. M. Flegal, D. Nicholls, and A. A. Jackson, "Body mass index cut offs to define thinness in children and adolescents: international survey," British Medical Journal, vol. 335, no. 7612, pp. 194-197, 2007.

[39] E. Goksör, M. Åmark, B. Alm, P. M. Gustafsson, and G. Wennergren, "The impact of pre- and post-natal smoke exposure on future asthma and bronchial hyper-responsiveness," Acta Paediatrica, vol. 96, no. 7, pp. 1030-1035, 2007.

[40] S. Pattenden, T. Antova, M. Neuberger et al., "Parental smoking and children's respiratory health: independent effects of prenatal and postnatal exposure," Tobacco Control, vol. 15, no. 4, pp. 294-301, 2006.

[41] F. Rasmussen and M. Johansson, “The relation of weight, length and ponderal index at birth to body mass index and overweight among 18-year-old males in Sweden," European Journal of Epidemiology, vol. 14, no. 4, pp. 373-380, 1998.

[42] R. P. Troiano and K. M. Flegal, "Overweight children and adolescents: description, epidemiology, and demographics," Pediatrics, vol. 101, no. 3, pp. 497-504, 1998.

[43] W. H. Dietz Jr. and S. L. Gortmaker, "Do we fatten our children at the television set? Obesity and television viewing in children and adolescents," Pediatrics, vol. 75, no. 5, pp. 807-812, 1985.

[44] T. N. Robinson, "Reducing children's television viewing to prevent obesity: a randomized controlled trial," Journal of the American Medical Association, vol. 282, no. 16, pp. 1561-1567, 1999.
[45] R. Grazuleviciene, A. Danileviciute, R. Nadisauskiene, and J. Vencloviene, "Maternal smoking, GSTM1 and GSTT1 polymorphism and susceptibility to adverse pregnancy outcomes," International Journal of Environmental Research and Public Health, vol. 6, no. 3, pp. 1282-1297, 2009.

[46] M. Mund, F. Louwen, D. Klingelhoefer, and A. Gerber, "Smoking and pregnancy - a review on the first major environmental risk factor of the unborn," International Journal of Environmental Research and Public Health, vol. 10, no. 12, pp. 6485-6499, 2013.

[47] S.-C. Chae, B. L. Park, C.-S. Park et al., "Putative association of RUNX1 polymorphisms with IgE levels in a Korean population," Experimental \& Molecular Medicine, vol. 38, no. 5, pp. 583-588, 2006.

[48] F. D. Gilliland, Y. Li, L. Dubeau et al., "Effects of glutathione S-transferase M1, maternal smoking during pregnancy, and environmental tobacco smoke on asthma and wheezing in children," The American Journal of Respiratory and Critical Care Medicine, vol. 166, no. 4, pp. 457-463, 2002.

[49] J. D. Hayes and R. C. Strange, "Glutathione S-transferase polymorphisms and their biological consequences," Pharmacology, vol. 61, no. 3, pp. 154-166, 2000.

[50] M. Kabesch, C. Hoefler, D. Carr, W. Leupold, S. K. Weiland, and E. Von Mutius, "Glutathione S transferase deficiency and passive smoking increase childhood asthma," Thorax, vol. 59, no. 7, pp. 569-573, 2004.

[51] C. V. Breton, H. Byun, M. Wenten, F. Pan, A. Yang, and F. D. Gilliland, "Prenatal tobacco smoke exposure affects global and gene-specific DNA methylation," American Journal of Respiratory and Critical Care Medicine, vol. 180, no. 5, pp. 462467, 2009.

[52] G. Koshy, A. Delpisheh, and B. J. Brabin, "Dose response association of pregnancy cigarette smoke exposure, childhood stature, overweight and obesity," European Journal of Public Health, vol. 21, no. 3, pp. 286-291, 2011. 


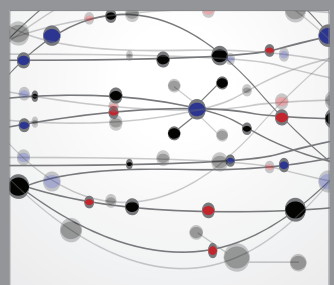

The Scientific World Journal
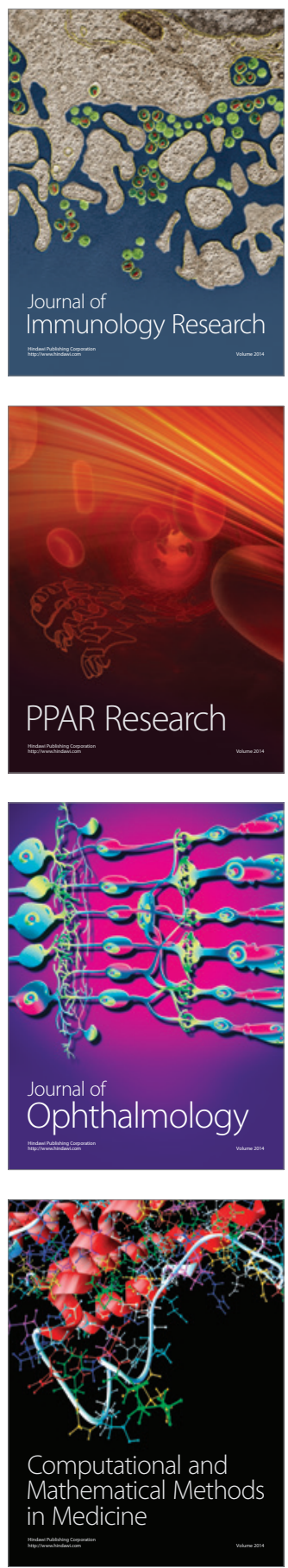

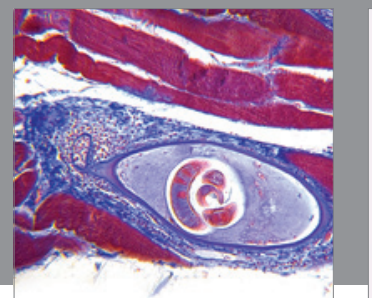

Gastroenterology

Research and Practice
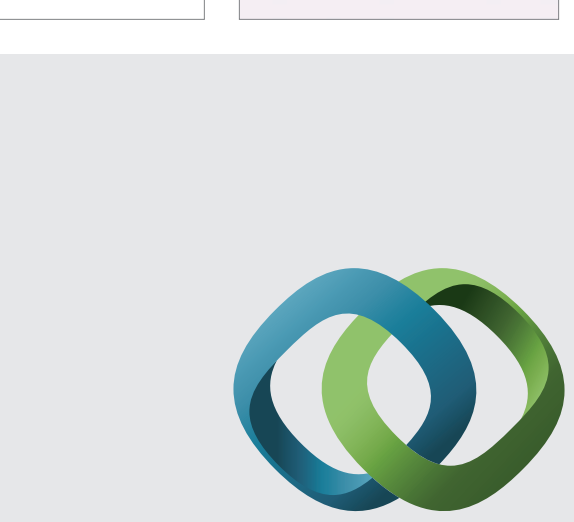

\section{Hindawi}

Submit your manuscripts at

http://www.hindawi.com
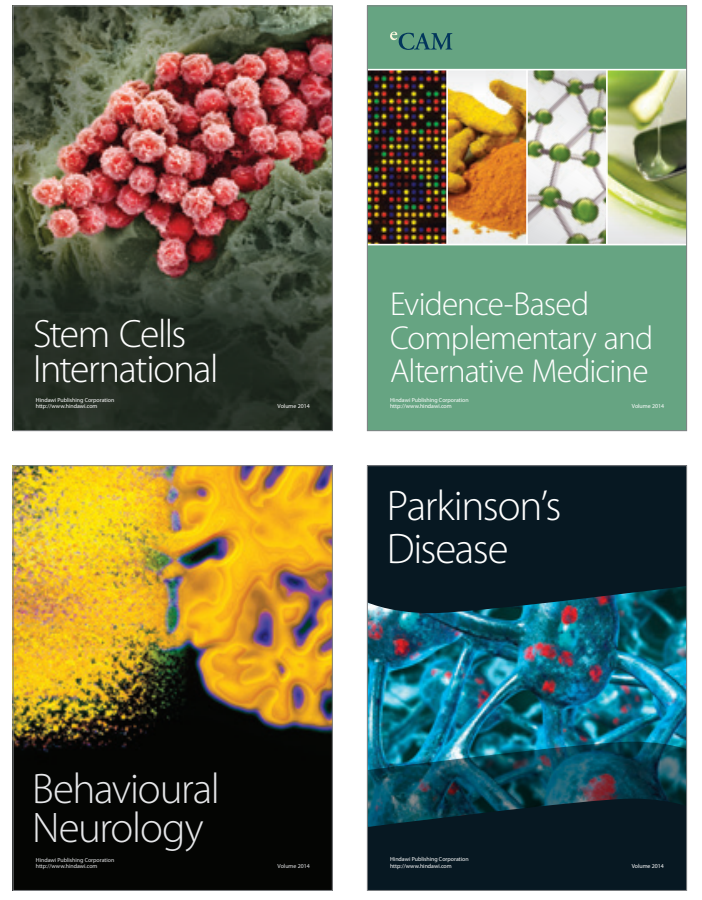
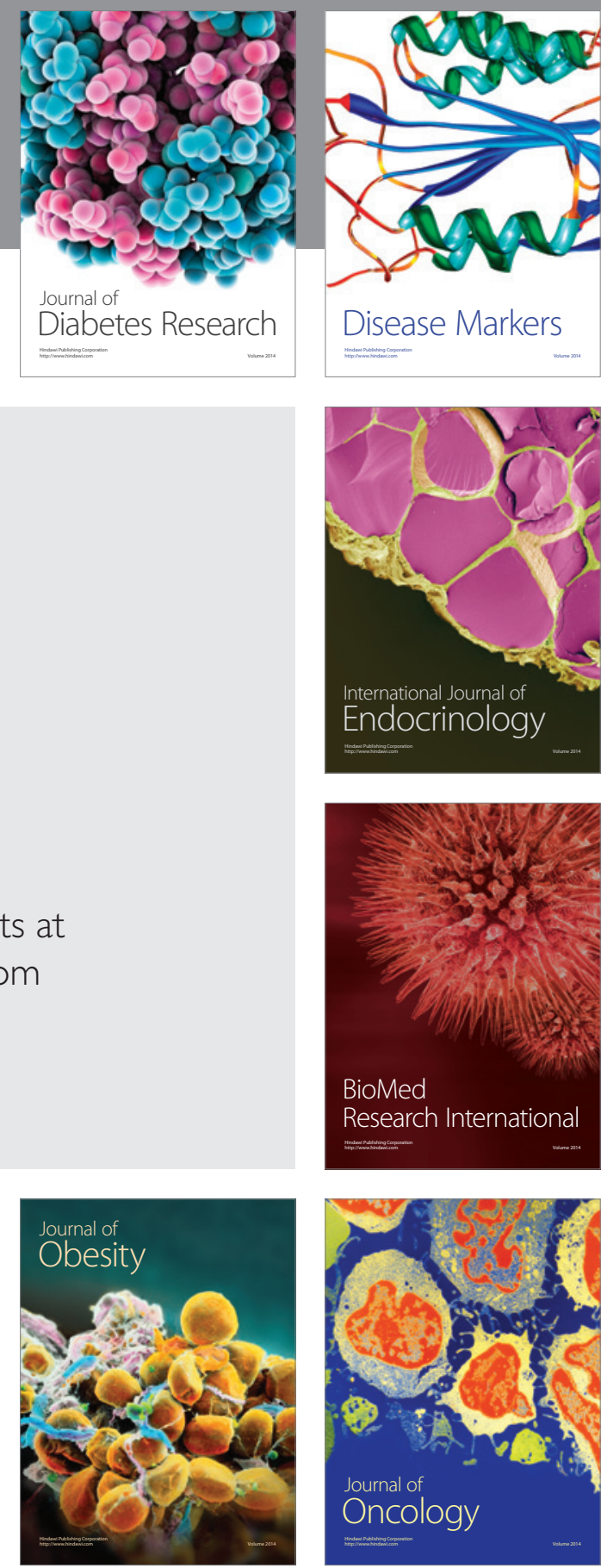

Disease Markers
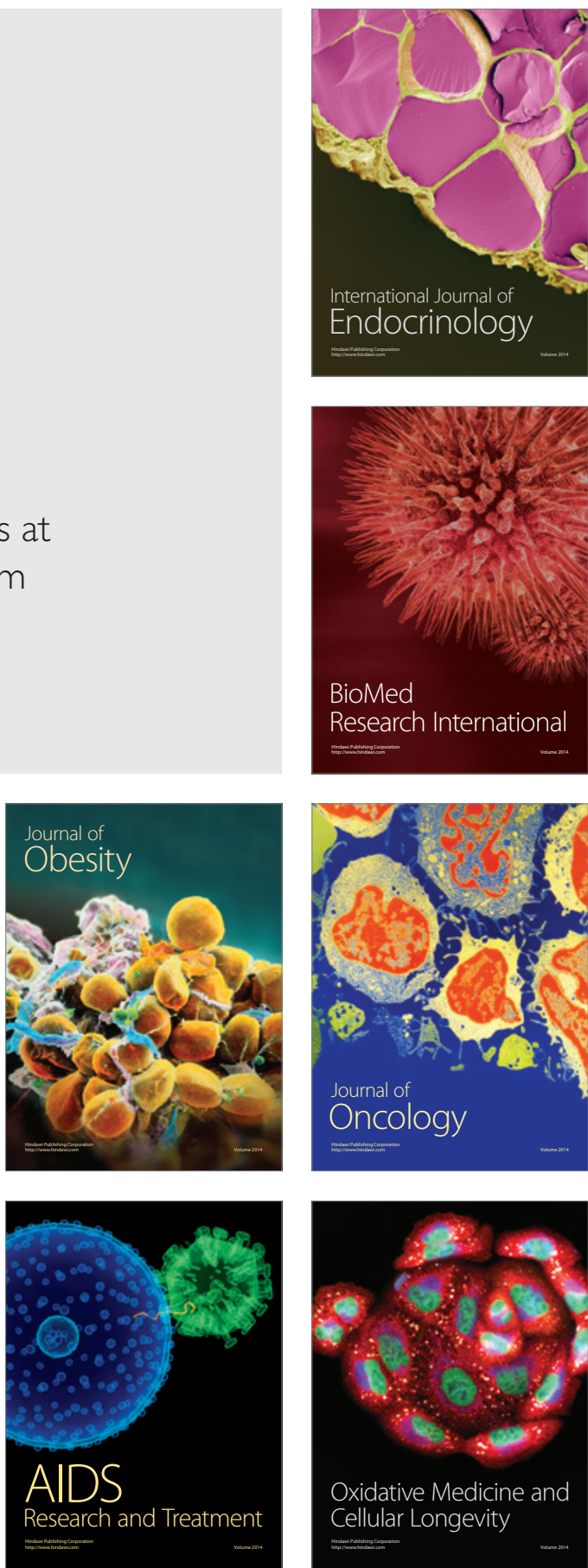